\title{
Rapid Analysis of SVOC in Aerosols by Desorption Electrospray Ionization Mass Spectrometry
}

\author{
Hong Chen, Mei Li, Ya-Ping Zhang, Xin Yang, Jin-Jun Lian, and \\ Jian-Min Chen \\ Department of Environmental Science and Engineering, Fudan University, Shanghai, China
}

Desorption electrospray ionization mass spectrometry (DESI-MS) was applied for the first time to the analysis of semivolatile organic compounds (SVOC) in atmospheric aerosols. We took polycyclic aromatic hydrocarbons (PAHs) as representatives of SVOCs. The DESI-MS conditions were optimized and the limit of detection for PAHs was about 10 pg with $5 \mathrm{~s}$ sampling time. PAHs from both laboratory-made biomass burning aerosols and ambient aerosols were selectively and rapidly analyzed without extraction or preconcentration. The observed PAH species and their relative ion intensities are discussed. This work demonstrates that DESI-MS is a promising method for rapid semiquantitative analysis of SVOC in atmospheric aerosols. (J Am Soc Mass Spectrom 2008, 19, 450-454) (c 2008 American Society for Mass Spectrometry

S emi-volatile organic compounds (SVOC) include a number of high molecular weight alkanes, polycyclic aromatic hydrocarbons (PAHs), organochlorine compounds, phthalic acid esters, aldehydes, ketones, and organic acids. They comprise major components in aerosols and play important roles in atmospheric chemistry [1-4]. Some of them, in particular PAHs, have been studied extensively [5-17] by scientists from different research fields because of their strong carcinogenic and mutagenic effects $[6,11,12]$. The traditional methods for the analysis of SVOC in aerosol samples, such as GC-MS, HPLC, capillary supercritical fluid chromatography, thin-layer chromatography, and capillary electrophoresis usually involve pretreatment procedures such as extraction, preconcentration and preseparation $[4,13,17]$. These procedures are labor intensive and time consuming. Moreover, they may cause the change or loss of certain components during analysis (for example, due to low extraction efficiency). As a result, alternative methods have been developed to analyze SVOC in aerosol samples such as thermal desorption and thermal extraction $[18,19]$.

Recently, Cooks et al. [20-23] reported a new soft ionization technique for the analysis of samples under ambient conditions: desorption electrospray ionization (DESI). The analyte surface is targeted directly by charged micro-droplets ejected from the electrospray nozzle under ambient pressure. Molecular ions are desorbed from the analyte surface and picked up by the micro-droplets and the auxiliary gas flow, and then

Address reprint requests to Dr. Xin Yang and Dr. Jian-Min Chen, Department of Environmental Science and Engineering, Fudan University, 220 Handan Road, Shanghai, 200433 China. E-mail: yangxin@fudan.edu.cn, jmchen@fudan.edu.cn. vacuumed to the inlet of the mass spectrometer [23]. The DESI phenomenon was observed for compounds ranging from nonpolar, small molecules such as lycopene [22], to larger biomolecules such as peptides and proteins at sensitivities as low as several pg in mass [24]. This simple and rapid analysis method has been applied to high-throughput metabolomics [25], explosives detection [26], and biological tissue imaging [27].

Here, we report the application of DESI-MS to the analysis of PAHs (as representatives of SVOCs) in atmospheric aerosols for the first time. PAHs from biomass burning aerosols and ambient aerosols were selectively and rapidly analyzed by DESI-MS without extraction or preconcentration. The limit of detection (LOD) for PAHs, the PAH species observed in the two types of samples, and their relative signal intensities are discussed.

\section{Experimental}

\section{Experimental Conditions of DESI}

DESI-MS analyses were carried out using a commercial ThermoFinnigan (San Jose, CA) LCQ Advantage ion trap mass spectrometer equipped with a DESI ion source, which was modified from the original ESI source by adding a 3D moving sample stage to the ESI manifold [21]. The sample stage includes a sample holder, a horizontal rotating stage, and a 3D linear moving stage to manually control the sprayer-samplemass spectrometer distance and the impact angles. Experimental parameters for DESI-MS were carefully optimized to enhance the signal intensity by using a standard PAH solution, with 16 EPA priority pollutants 
in methanol (EPA 610/525/550 PAH mixture, 100 $\mu \mathrm{g} / \mathrm{mL}$ for each $\mathrm{PAH}$, lot 323-55A), which was purchased from ChemService (West Chester, PA). The diluted standard PAH solution was deposited on the glass surface of microscope slide. The optimized operating parameters of DESI-MS are listed in Table 1. We tested methanol, hexane, cyclohexane, acetonitrile, acetic acid, ammonia/water, and their combinations as the spray solution and compared the signals in both positive ion and negative ion mass spectra. Methanol with $1 \%$ acetic acid gave the strongest signal for PAHs in positive ion mass spectra. The experiments were conducted in a fume hood with sufficient ventilation, and a respirator was used by the operator considering the toxicity of PAHs.

\section{Biomass Burning Aerosols}

Biomass burning aerosols were generated by the combustion of rice straw in a homemade burner in which the amount of the biomass material and the burning condition (flaming/smoldering) can be controlled. In this experiment, $20 \mathrm{~g}$ rice straw was burned under flaming conditions. The low ratio of $\mathrm{CO} / \mathrm{CO}_{2}$ in the gas phase by GC analysis indicated that the rice straw was burned completely. The rice straw was collected from the rural areas of Shanghai. The moisture content of the rice straw was around $11 \%$. Total suspended particulates (TSP) of the generated aerosols were collected on quartz fiber filters with a $90 \mathrm{~mm}$ diameter (Whatman Inc., Maidstone, UK) by a medium-volume aerosol sampler (Beijing Geological Instrument Factory, Beijing, China) at a flow rate of $100 \mathrm{~L} / \mathrm{min}$. After $5 \mathrm{~min}$ sampling duration, the filter was taken out. A $15 \mathrm{~mm} \times$ $15 \mathrm{~mm}$ piece was cut out and attached to the sample stage for DESI-MS analysis without extraction or preconcentration. For comparison, the rest of the sample was analyzed by GC-MS coupled with supercritical fluid extraction (SFE) [6, 17]. Typically, each DESI sampling spot in this analysis was about $1 \mathrm{~mm}^{2}$ in area and the sampling duration for each spot was 5 to $10 \mathrm{~s}$. DESI mass spectra were taken by scanning the whole sample surface and averaging the results for all spots.

Table 1. Optimum conditions for the DESI-MS analysis of PAHs

\begin{tabular}{ll}
\hline Solvent infusion rate & $2.5 \sim 12.5 \mu \mathrm{L} \cdot \mathrm{min}^{-1}$ \\
Electrospray voltage & $4.0 \sim 7.0 \mathrm{kV}$ \\
Sheath gas flow & $20 \sim 60$ (Arb.) \\
Auxiliary gas flow & $3 \sim 6$ (Arb.) \\
Incident angle $(\alpha)$ & $35^{\circ}$ \\
Distance from sample to ESI tip & $4 \sim 6 \mathrm{~mm}$ \\
Collection angle $(\beta)$ & $55^{\circ}$ \\
Distance from sample to MS inlet & $1 \sim 3 \mathrm{~mm}$ \\
Heating capillary temperature & $200 \sim 350{ }^{\circ} \mathrm{C}$ \\
Capillary voltage & $20 \sim 50 \mathrm{~V}$ \\
Tube lens voltage & $10 \sim 60 \mathrm{~V}$ \\
Sampling spot size & $\sim 1 \mathrm{~mm}$ \\
Single spot sampling time & $5 \sim 10 \mathrm{~s}$ \\
\hline
\end{tabular}

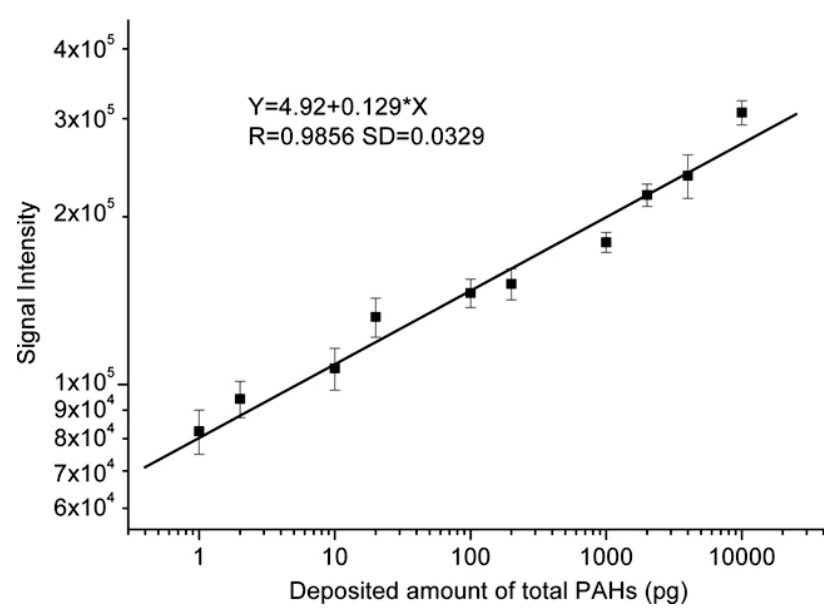

Figure 1. Signal intensity versus amount of total PAHs deposited.

\section{Ambient Aerosols}

The ambient aerosols were collected on a building roof ( $\sim 15 \mathrm{~m}$ high) in Fudan University. The sampling site is representative of urban Shanghai, with mixing of residential, traffic, and construction sources [28]. Particulate matter with a diameter less than or equal to $2.5 \mu \mathrm{m}$ $\left(\mathrm{PM}_{2.5}\right)$ samples were collected on quartz filters (Whatman Inc., Maidstone, UK) by the same medium-volume sampler as used in biomass burning aerosol sampling at a flow rate of $77.54 \mathrm{~L} / \mathrm{min}$. These ambient aerosols were collected from 9:09 AM January 18, 2007 to 9:36 AM January 19, 2007. The sample was transported to our laboratory in sealed plastic bags immediately after sampling and stored at $-18{ }^{\circ} \mathrm{C}$ for later analysis.

\section{Results and Discussion}

\section{LOD and Dynamic Range for PAHs}

Under the optimized operating condition, all the 16 PAHs were observed in the DESI-MS spectra of standard samples although some of them are isomers and thus overlapped. All the PAH ion signals are in the forms of molecular ions $\left(\mathrm{M}^{+}\right)$or protonated molecular ions $\left([\mathrm{M}+\mathrm{H}]^{+}\right)$, making the spectral assignment rather straightforward. The mass to charge ratio $(\mathrm{m} / \mathrm{z})$ for each $\mathrm{PAH}$ ion detected in the DESI-MS spectra is described below. To test the LOD and the dynamic range for this method, calibration was carried out between the total PAH signal intensity and the amount of PAHs deposited. As shown in Figure 1, a dynamic range of three orders of magnitude was observed. The LOD is about $10 \mathrm{pg}$ with $5 \mathrm{~s}$ sampling time using this particular mass spectrometer.

\section{PAHs in Biomass Burning Aerosols}

PAHs can be generated by natural or anthropogenic sources. Biomass burning of agricultural residue disposal produces different types of PAHs and is regarded as one of the major anthropogenic sources [29-31]. In 

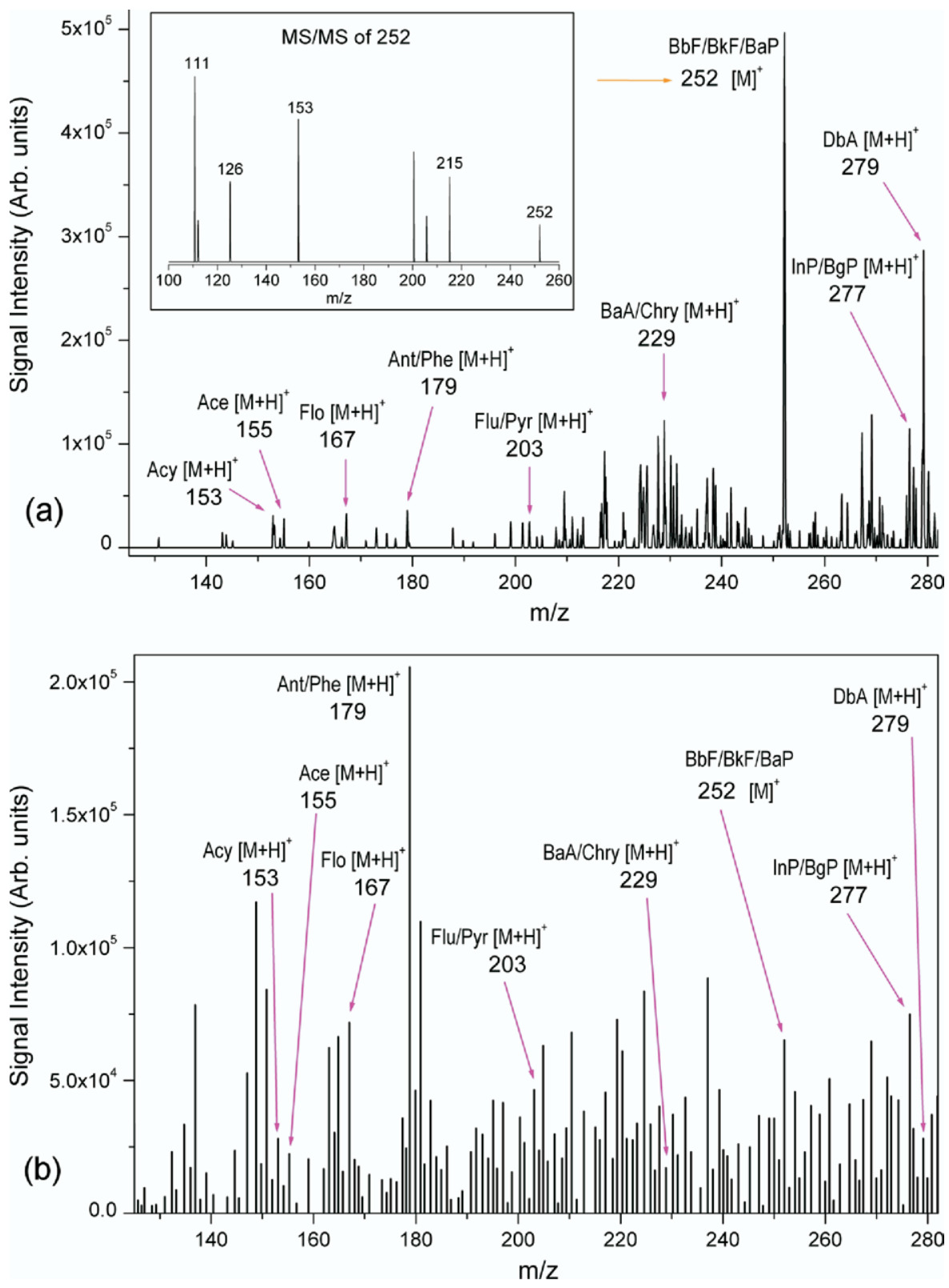

Figure 2. (a) A typical DESI mass spectrum of PAHs from biomass burning aerosol, using $1 \%$ acetic acid in methanol as the spray solution. Only ions representing the molecules among 16 U.S. EPA "priority PAH pollutants" were marked. The inset shows the MS/MS of the $m / z=252$ ion. (b) DESI mass spectrum of PAHs from ambient aerosol.

this work, we used laboratory-made aerosols from rice straw burning as the biomass burning samples. Figure 2a shows a typical positive ion DESI spectrum of PAHs from such laboratory-made aerosols. Only the 16 U.S. EPA priority PAH pollutants were studied in this experiment. Each possible molecular ion or protonated molecular ion was confirmed by further MS/MS fragmentation analysis. The identities for $m / z=153,155$, 167,279 ions are $[\mathrm{M}+\mathrm{H}]^{+}$of acenaphthylene (Acy), acenaphthene (Ace), fluorene (Flo), dibenzo[a,h]anthracene (DbA), respectively. The $\mathrm{m} / \mathrm{z}=179$ ion is due to the overlap of the $[\mathrm{M}+\mathrm{H}]^{+}$of anthracene (Ant) and phenanthrene (Phe). Similarly, the $m / z=203$ ion is due to the overlap of $[\mathrm{M}+\mathrm{H}]^{+}$of fluoranthene (Flu) and pyrene (Pyr). The $m / z=229$ ion is due to the overlap of $[\mathrm{M}+\mathrm{H}]^{+}$of benzo[a]anthracene $(\mathrm{BaA})$ and chrysene (Chry). The $m / z=277$ ion is due to the overlap of [M + $\mathrm{H}^{+}$of indeno[1,2,3cd]pyrene (InP) and benzo[g,h,i]perylene $(\mathrm{BgP})$. For these overlapped ion signals, the contribution for each species can be estimated from the MS/MS fragmentation spectra. For example, the $\mathrm{m} / \mathrm{z}$ for the molecular ions of benzofluoranthene $(\mathrm{BbF})$, benzo[k] fluoranthene $(\mathrm{BkF})$, and benzo[a]pyrene $(\mathrm{BaP})$ are all 252. However, the abundant product ion at $m / z=111$ in the MS/MS spectrum suggested that BkF may make a major contribution to the 252 peak in this sample [32]. 
Table 2. Total PAH concentrations measured by DESI-MS and GC-MS

\begin{tabular}{ccc}
\hline & \multicolumn{2}{c}{ Total PAH concentration $(\mu \mathrm{g} / \mathrm{g})$} \\
\cline { 2 - 3 } Aerosol sample & DESI-MS & GC-MS \\
\hline \hline 1 & 1020 & 990 \\
2 & 380 & 800 \\
3 & 240 & 280 \\
4 & 490 & 510 \\
5 & 391 & 823 \\
6 & 564 & 648 \\
7 & 549 & 559 \\
\hline
\end{tabular}

We did not observe the naphthalene (Nap) molecular ion here, probably because of its relatively high vapor pressure and extremely low concentration in the particle phase [33]. The dominant PAH peaks in Figure 2a clearly show that the optimum DESI method can selectively analyze PAHs in aerosol samples without extraction or preconcentration. This is important for trace analysis of complex environmental samples.

For the cases of natural surfaces samples, such as aerosol samples, use of internal standards does not give strictly quantitative results [22]. Here, we used a standard PAH solution deposited on the glass surface of the microscope slide for calibration (Figure 1) and attempted to gain a semiquantitative estimation of the total PAH concentrations from the ion signal intensities. The differences between the glass surface and the sample surface as well as the matrix effect of the aerosol sample could influence the quantitative accuracy of the DESI measurements of analytes. The total mass concentrations of PAHs $\left(\mathrm{m}_{\mathrm{PAH}} / \mathrm{m}_{\mathrm{TSP}}\right)$ in biomass burning aerosols measured by DESI-MS and SFE/GC-MS method are listed in Table 2. The DESI-MS measurements are in reasonable agreement with those by the GC-MS.

In Figure 2a, the intensities of ions due to 5- and 6-ring PAHs $(252,277$, and 279) are much stronger than those of the 3-ring PAHs $(153,155,167,179)$. Comparing the relative responses factors of PAHs with known concentrations in the DESI mass spectra, we conclude that the mass concentrations of large PAHs are higher than those of small PAHs in aerosols from rice straw burning. Again, the DESI-MS observations agree well with those from the GC-MS measurements: Mass concentrations of the 5- and 6-ring PAHs are about three times those of 3-ring PAHs.

\section{PAHs in Ambient Aerosols}

The PAHs in ambient aerosol were also sampled and analyzed by DESI-MS, as shown in Figure $2 b$. The compositions of ambient aerosols are relatively complex, so for clarity, only the histogram is presented here. The total PAHs concentration was estimated at $17 \mu \mathrm{g} / \mathrm{g}$ in $\mathrm{PM}_{2.5}$ or $5.5 \mathrm{ng} / \mathrm{m}^{3}$ in air from the DESI-MS analysis, which agrees well with the GC-MS measurement (6.6 $\left.\mathrm{ng} / \mathrm{m}^{3}\right)$. The PAH species observed in biomass burning and ambient aerosol samples have different relative ion intensities. In ambient sample, the ion signal intensities for the observed PAHs are close to one another except for the strong 179 (Ant and Phe) ion. The differences between the two types of samples could be due to different pollutant sources and evolution pathways as well as the degradation of larger PAHs in the ambient aerosols.

\section{Conclusions}

This study demonstrates that DESI-MS is a powerful tool for the rapid analysis of SVOC in atmospheric aerosols, at least for PAHs. The optimized experimental conditions can selectively detect target components in a complex system. Because of the high sensitivity and selectivity, samples can be directly analyzed without extraction or preconcentration, which prevents analyte loss or change and thus yields more accurate aerosol composition. Since DESI is a soft ionization method, most of the components in the analyte samples can retain their molecular structures with little or no fragmentation, making the mass spectrum interpretation relatively easy. The small sampling areas required can be useful for trace analysis. These results render DESI-MS a promising method for the analysis of other SVOC, especially those compounds that are prone to loss or chemical change in the pretreatment procedures.

\section{Acknowledgments}

The authors acknowledge support for this work by the Cheung Kong Scholars Program from Li Ka Shing Foundation and the Chinese Ministry of Education, National Science Foundation of China (no.40533017, no.40605001). The authors thank Professor Guoshun Zhuang and Mr. Bing Hou for the ambient aerosol sampling. XY thanks Drs. Yuri Desyaterik and Alex Laskin at Pacific Northwest National Laboratory (U.S.A.) for helpful discussions.

\section{References}

1. Finlayson-Pitts, B. J.; Pitts, J. N. Chemistry of the Upper and Lower Atmosphere: Theory, Experiments, and Applications; Academic Press: New York, 2000; p. 412.

2. Andreae, M. O. Aerosols before Pollution. Science 2007, 315, 50-51.

3. Donahue, N. M.; Robinson, A. L.; Stanier, C. O.; Pandis, S. N. Coupled Partitioning, Dilution, and Chemical Aging of Semivolatile Organics. Environ. Sci. Technol. 2006, 40, 2635-2643.

4. Peltonen, K.; Kuljukka, T. Air Sampling and Analysis of Polycyclic Aromatic-Hydrocarbons. J. Chromatogr. A 1995, 710, 93-108.

5. Vo-Dinh, T. Chemical Analysis of Polycyclic Aromatic Compounds; Wiley-Interscience: New York, 1989; pp. 4-9.

6. Lee, M. L.; Novotny, M. V.; Bartle, K. D. Analytical Chemistry of Polyaromatic Hydrocarbons; Academic Press: New York, 1981; pp 51-55.

7. Wang, G. H.; Kawamura, K.; Lee, S.; Ho, K. F.; Cao, J. J. Molecular, Seasonal, and Spatial Distributions of Organic Aerosols from Fourteen Chinese Cities. Environ. Sci. Technol. 2006, 40, 4619-4625.

8. Feng, J. L.; Chan, C. K.; Fang, M.; Hu, M.; He, L. Y.; Tang, X. Y. Characteristics of Organic Matter in PM2.5 in Shanghai. Chemosphere 2006, 64, 1393-1400.

9. Zhang, Y. X.; Tao, S.; Cao, J.; Coveney, R. M. Emission of Polycyclic Aromatic Hydrocarbons in China by County. Environ. Sci. Technol. 2007 $41,683-687$.

10. Kumata, H.; Uchida, M.; Sakuma, E.; Uchida, T.; Fujiwara, K.; Tsuzuki, M.; Yoneda, M.; Shibata, Y. Compound Class Specific C-14 Analysis of Polycyclic Aromatic Hydrocarbons Associated with PM10 and PM1.1 
Aerosols from Residential Areas of Suburban Tokyo. Environ. Sci. Technol. 2006, 40, 3474-3480.

11. Loutfy, N.; Fuerhacker, M.; Tundo, P.; Raccanelli, S.; Ahmed, M. T. Monitoring of Polychlorinated Dibenzo-p-Dioxins and Dibenzofurans, Dioxin-like PCBs, and Polycyclic Aromatic Hydrocarbons in Food and Feed Samples from Ismailia City, Egypt. Chemosphere 2007, 66, 19621970.

12. de Kok, T. M. C. M.; Driece, H. A. L.; Hogervorst, J. G. F.; Briede, J. J. Toxicological Assessment of Ambient and Traffic-Related Particulate Matter: A Review of Recent Studies. Mutat. Res./Rev. Mutat. Res. 2006, 613, 103-122.

13. Poster, D. L.; Schantz, M. M.; Sander, L. C.; Wise, S. A. Analysis of Polycyclic Aromatic Hydrocarbons (PAHs) in Environmental Samples: A Critical Review of Gas Chromatographic (GC) Methods. Anal. Bioanal. Chem. 2006, 386, 859-881.

14. Chang, K. F.; Fang, G. C.; Chen, J. C.; Wu, Y. S. Atmospheric Polycyclic Aromatic Hydrocarbons (PAHs) in Asia: A Review from 1999 to 2004. Environ. Pollut. 2006, 142, 388-396.

15. Ren, Y.; Cheng, T. T.; Chen, J. M. Polycyclic Aromatic Hydrocarbons in Dust from Computers: One Possible Indoor Source of Human Exposure. Atmos. Environ. 2006, 40, 6956-6965.

16. Ren, Y.; Zhang, Q.; Chen, J. Distribution and Source of Polycyclic Aromatic Hydrocarbons (PAHs) on Dust Collected in Shanghai, People's Republic of China. Bull. Environ. Contam. Toxicol. 2006, 76, 442-449.

17. Ren, Y.; Lian, J. J.; Xue, H. X.; Chen, J. M.; Cheng, T. T. Determination of PAHs in Dust from Shanghai by Optimized SFE and GC/MS. Ann. Chim. 2006, 96, 669-680.

18. Ho, S. S. H.; Yu, J. Z. In-injection Port Thermal Desorption and Subsequent Gas Chromatography-Mass Spectrometric Analysis of Polycyclic Aromatic Hydrocarbons and n-Alkanes in Atmospheric Aerosol Samples. J. Chromatogr. A 2004, 1059, 121-129.

19. Hays, M. D.; Lavrich, R. J. Developments in Direct Thermal Extraction Gas Chromatography-Mass Spectrometry of Fine Aerosols. Trends Anal. Chem. 2007, 26, 88-102.

20. Cooks, R. G.; Ouyang, Z.; Takats, Z.; Wiseman, J. M. Ambient Mass Spectrometry. Science 2006, 311, 1566-1570.

21. Takats, Z.; Wiseman, J. M.; Cooks, R. G. Ambient Mass Spectrometry Using Desorption Electrospray Ionization (DESI): Instrumentation, Mechanisms and Applications in Forensics, Chemistry, and Biology. J. Mass Spectrom. 2005, 40, 1261-1275.
22. Takats, Z.; Wiseman, J. M.; Gologan, B.; Cooks, R. G. Mass Spectrometry Sampling under Ambient Conditions with Desorption Electrospray Ionization. Science 2004, 306, 471-473.

23. Venter, A.; Sojka, P.E.; Cooks, R. G. Droplet Dynamics and Ionization Mechanisms in Desorption Electrospray Ionization Mass Spectrometry. Anal. Chem. 2006, 78, 8549-8555.

24. Shin, Y. S.; Drolet, B.; Mayer, R.; Dolence, K.; Basile, F. Desorption Electrospray Ionization-Mass Spectrometry of Proteins. Anal. Chem. 2007, 79, 3514-3518.

25. Chen, H. W.; Pan, Z. Z.; Talaty, N.; Raftery, D.; Cooks, R. G. Combining Desorption Electrospray Ionization Mass Spectrometry and Nuclear Magnetic Resonance for Differential Metabolomics without Sample Preparation. Rapid Commun. Mass Spectrom. 2006, 20, 1577-1584.

26. Cotte-Rodriguez, I.; Cooks, R. G. Nonproximate Detection of Explosives and Chemical Warfare Agent Simulants by Desorption Electrospray Ionization Mass Spectrometry. Chem. Commun. 2006, 2968-2970.

27. Wiseman, J. M.; Ifa, D. R.; Song, Q. Y.; Cooks, R. G. Tissue Imaging at Atmospheric Pressure Using Desorption Electrospray Ionization (DESI) Mass Spectrometry. Angew. Chem. Int. Ed. 2006, 45, 7188-7192.

28. Wang, Y.; Zhuang, G. S.; Zhang, X. Y.; Huang, K.; Xu, C.; Tang, A. H. Chen, J. M.; An, Z. S. The Ion Chemistry, Seasonal Cycle, and Sources of PM2.5 and TSP Aerosol in Shanghai. Atmos. Environ. 2006, 40, 2935 2952.

29. Hudson, P. K.; Murphy, D. M.; Cziczo, D. J.; Thomson, D. S.; de Gouw, J. A.; Warneke, C.; Holloway, J.; Jost, J. R.; Hubler, G. Biomass-Burning Particle Measurements: Characteristic Composition and Chemical Processing. J. Geophys. Res. 2004, 109 D23S27, doi:10.1029/2003JD004398.

30. Jenkins, B. M.; Jones, A. D.; Turn, S. Q.; Williams, R. B. Emission Factors for Polycyclic Aromatic Hydrocarbons from Biomass Burning. Environ. Sci. Technol. 1996, 30, 2462-2469.

31. Yang, H. H.; Tsai, C. H.; Chao, M. R.; Su, Y. L.; Chien, S. M. Source Identification and Size Distribution of Atmospheric Polycyclic Aromatic Hydrocarbons During Rice Straw Burning Period. Atmos. Environ. 2006, 40, 1266-1274.

32. Liu, K. L.; Heltsley, R.; Zou, D. H.; Pan, W. P.; Riley, J. T. Polyaromatic Hydrocarbon Emissions in Fly Ashes from an Atmospheric Fluidized Bed Combustor Using Thermal Extraction Coupled with GC/TOF-MS Energy Fuels 2002, 16, 330-337.

33. Fraser, M. P.; Cass, G. R.; Simoneit, B. R. T.; Rasmussen, R. A. Air Quality Model Evaluation Data for Organics. 5. $\mathrm{C}_{6}-\mathrm{C}_{22}$ Nonpolar and Semipolar Aromatic Compounds. Environ. Sci. Technol. 1998, 32, 1760 1770 . 